\title{
Innovation \& Entrepreneurship "Regenerate" A Fashion Entrepreneur Has a Flair for Fighting Poverty
}

\author{
Zuer Wang ${ }^{1}$, Ziou Dong ${ }^{2}$
}

${ }^{1}$ Ashbury college, Ottawa, Canada, zuer.wang@ashbury.ca

${ }^{2}$ Beijing Concord College of Sino-Canada,Beijing, China,2022763897@qq.com

\begin{abstract}
This Work, titled 'Innovation and Entrepreneurship -- Regenerate', describes the start-up of an eco-friendly clothing brand, 'Regenerate', its future direction and suggestions. Paper identifies the suitable business partners for the brand by analyzing its strengths and weaknesses and different business models. It plans future sales method with the help of comprehensive market research, helps brands "Regenerate" to find brand value and achieve brand's goal, from a small and local company to a large and international brand. The main significance of the research is firstly to analyze how an innovative company should develop with the help of actual examples, and secondly to give guidance and inspiration to entrepreneurs who are starting businesses or have intentions.
\end{abstract}

Keywords: Entrepreneurship, innovation, collaboration, market analysis, business strategy.

\section{BRAND INTRODUCTION}

Living in the 21 st century, many technologies that our ancestors could not even imagine have been realized in our age. Due to the advancement of technology, young entrepreneurs with novel ideas have the opportunity to display their talents. As the founder of the brand "Regenerate", May is a successful entrepreneur dedicated to changing society and improving the environment through the entrepreneurial spirit of the 21 st century.

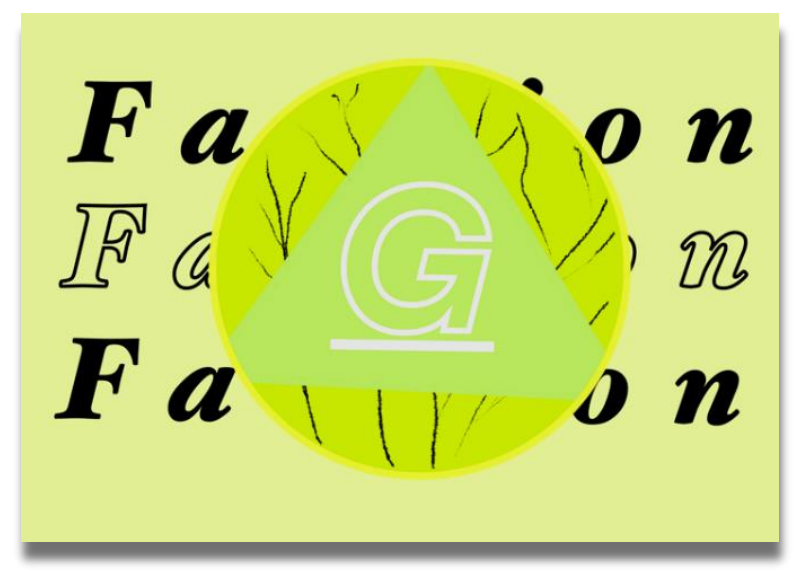

Figure 1 Brand "Regenerate" LOGO Create by Author

We will deeply analyze "Regenerate" from 6 parts and explain how the brand works. Including brand introduction, brand analysis, business strategy, market research, final business plan and future goals
[1]."Regenerate" is a British clothing brand founded by May. It focuses on making clothes with environmentally friendly materials and selling them globally. Part of the income is donated to poor areas to help improve people's lives. This model has not only made efforts for the global ecological environment, but also improved the society which is a extremely novel and meaningful idea. The development of the brand is fairly smooth, and the two concepts of environmental protection and donation have also attracted some celebrities. The brand has established a mature system in the UK relying on the celebrity's reputation. However, promoting the brand globally is not a simple process, it requires a lot of analysis and investigation to prepare for the final business plan. The three problems currently "Regenerate" is facing are

1.Small scale and too local

2. No long-term partners

3. Scarce professional talents and managers.

Therefore, May's initial idea is to cooperate with the international luxury brand Burberry and use their mature operation model to help "Regenerate" spread to the world.

\section{ANALYZE}

\subsection{Pros and Cons}

The Mission of this company is use of renewable and 
socially neglected materials to create a popular clothing brand for young people around the world. Vision is to help people in poor areas and protect the social environment. Regarding brand analysis, we first use SWOT to analyze. For the strength, the core of her brand is environmental protection and recycle. The brand will do public welfare activities; thus, it is going to attract more celebrities and they may support out brand. Therefore, they can improve brand awareness. Second, once cooperate with Burberry, it can drive the development of their brand. The last one is May's previous learning experience at Hive and her commitment to social entrepreneurship. Weaknesses of this brand are:1. The company is relatively small and local and they are not sure if they can work with Burberry for a long time. Then due to the fact that "Regenerate" is a small company so they don't have a complete management system, even the production system. On the other hand, brand also have many threats. More and more similar brands try to copy it. If they don't develop rapidly, the company may be eliminated. In addition, May has to follow closely with fashion. Otherwise, she will lose a lot of customers. The third one is cultures. Different countries have different cultures. She has to understand the cultures of different countries, avoiding her products infringe upon the culture of other countries. Last one is stability of cooperate with Burberry. Fortunately, "Regenerate" is also an extremely promising brand with opportunities. It may be a company that has a long-term positive social impact and become a role model for the industry [2].

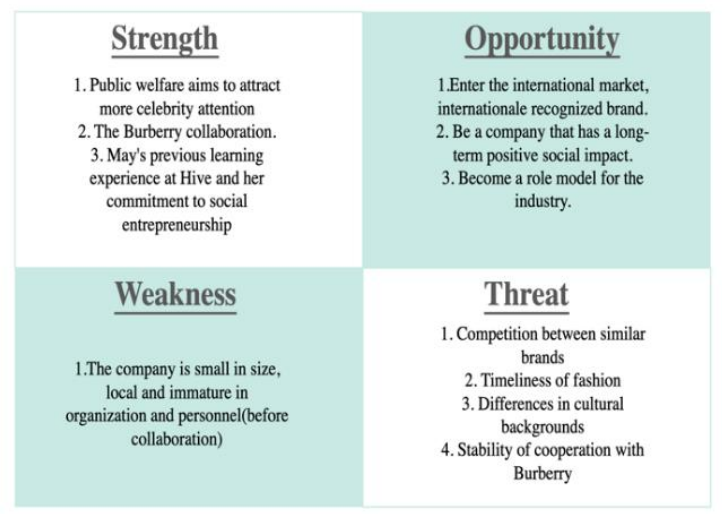

Figure 2 SWOT Model Anaylyze For Brand "Regenerate" Create by Author

\subsection{Brand specialization}

The VRINO model also helps us understand more about "regeneration". "V" stands for "Value". Clothes are made of environmentally friendly materials and products promote the development. "R" means rare. Every piece of clothing is carefully designed by the designer and their ideas are unique and their thoughts. "I" and "N" have the similar means. It means imitability. Every designer has a different idea. They have different understanding of fashion, so it not easy to copy. Last one "O" means organization. It has strong organization, after the cooperation with Burberry which is a successful globe brand.

\subsection{Brand Operation}

Then, we use Pestle to analyze the situation of May and Regenerate in six aspects. For politics, companies need to pay attention to the import and export treaties and tax regulations of different countries. Economic prospects are good for Regenerate. Through the investigation, they found that the market and sales of clothing in the world are increasing greatly. Among them, the largest markets are distributed in the United States, China and Japan, which can also be a reference for their strategy. For social conditions, the most important thing is to understand the current fashion elements and trends, to ensure that they can produce the clothes that best suit the current situation. In addition, different social and cultural backgrounds are also very important for a clothing brand. In terms of technology, because the brand adopts very novel ideas, it requires the company to have effective production workshop and mature technology to ensure that it can afford the orders from the world. Law is also an important part, and the Consumer and Producer Protection Act plays a role in this. It protects both the interests of customers and the interests of companies [3]. Finally, environmental factors. Different regions and different climates have different requirements for clothing. It is necessary to consider in advance whether sudden environmental problems will affect the operation of the company.

\section{BUSINESS STRATEGY}

For their business strategy, their key partner is Burberry, which provides a good platform for us to sell products. At the same time, it also provides a mature and complete business chain, from suppliers to factories to sales. Meantime, one of the important partners is the shipping company, which ensures that products can be delivered to customers smoothly and safely. What is the main goal for "Regenerate"? The first priority is to make clothes. Secondly, they need to ensure customer satisfaction to help us become a better and more excellent brand. There must be a manual workshop, where can make clothes, the second is the shipping company, and the last is after-sales service, which to a large extent lays the foundation for the success of a service company. They realize the value of their company by making the most fashionable and comfortable clothing. At present, their target customers are Burberry's original customers and all the people who have the pursuit of fashion. They hope that the company and customers can establish a relationship of trust, and committed to providing 24-hour global after-sales service to ensure that customers can 
solve the problems related to the products in the first time [3].

\section{MARKETING}

In order to make "Regenerate" have a more effective business strategy, company conducted market research. The first market survey reflects the market situation of the world's luxury goods. The overall phenomenon is rising and expanding. Although there is a small decline due tocovid-19 from 2019 to 2020 , it does not affect their discovery of the potential of luxury clothing. " The world luxury market is promising and will have a very high income 10 years from now, in 2030. They also look at the situation about the world garment industry from 2016 to 2020. In recent years, the garment industry has developed rapidly, especially in 2020, with a very large growth [4,5]." This is a good sign for "Regenerate" and shows the future of world apparel. In the second market study, they focused on Burberry, its success directly affects the success of the company. The good news is that as one of the most well-known luxury brands in the world, Burberry's revenue is guaranteed [6]. The World income and sales of Burberry have continued to grow in recent years. In addition, they searched Chinese and British websites for some comments on Burberry, and most of them were very positive. In recent years, Burberry has also begun to design a lot of T-shirts, hoodies, bags, shoes and so on that are in line with the current fashion. It's a great fit for Regenerate and working with Burberry is the first step towards becoming an internationally successful brand $[5,7]$.

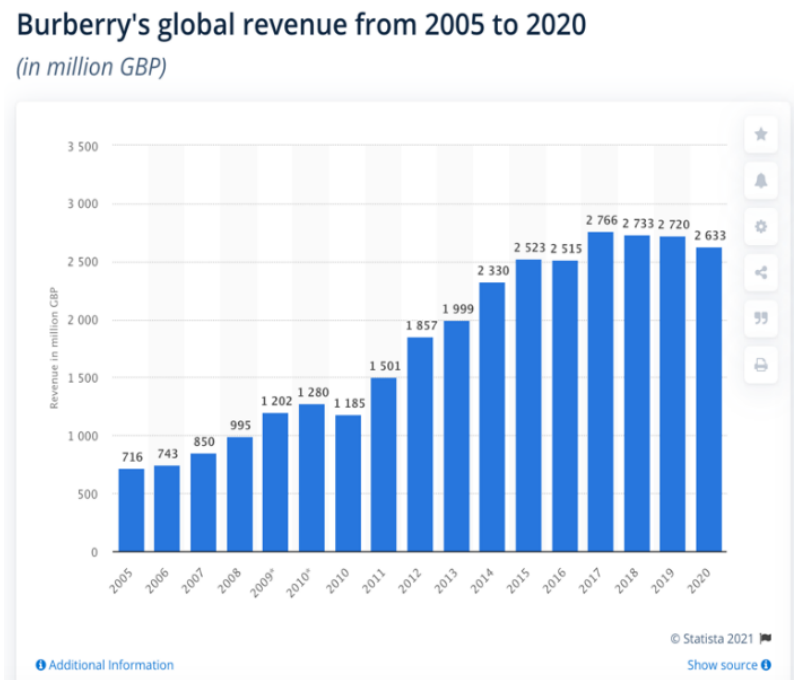

Figure 3 Burberry's global revenue from 2005 to 2020 Create by Author

Finally, they asked people what they thought about eco-friendly clothing and social donations. Most people are interested, some have no idea what it is, some are not interested, and the rest don't care. Although this is a good phenomenon for Regenerate, it is not enough. If you want to succeed, you need to work harder to promote this idea.
Most people agree to turn their consumption into a social donation. Some are not interested in, and some are against.

\section{Views on recycled clothing}

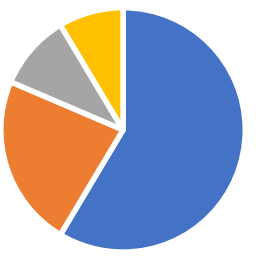

$$
\begin{aligned}
& \text { interested in } \quad \text { no idea } \\
& \text { Not interested in } \quad \text { Don't care }
\end{aligned}
$$

Figure 4 Market research - Interest in recycling clothing Create by Author

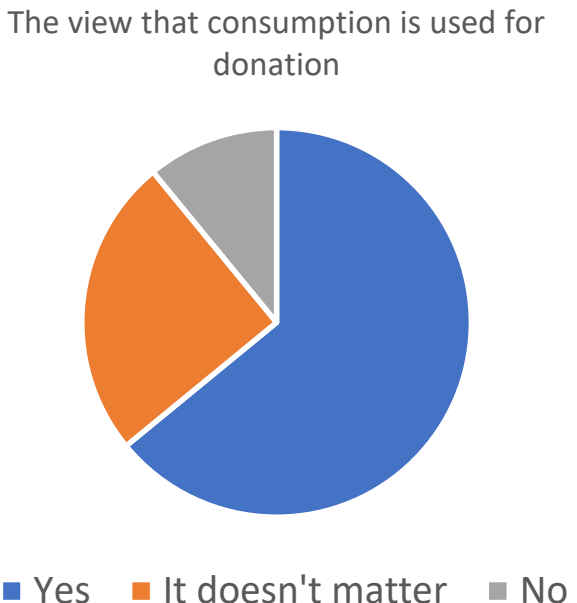

Figure 5 Market research - Interest in donation Create by Author

These two points are the company in the future publicity and advertising need to pay attention to. The main trend for current market are 1. People tend to shop online [8].2. The luxury goods market is on the rise. 3 . Some people agree with the idea of environment-friendly clothes, which needs to be further strengthened.4. People's enthusiasm for social donations is not high and needs to be strengthened. As a conclusion, "Regenerate" needs to improve online sales, maintains cooperation with international brands and promotes environmentally friendly materials and social donations as much as possible. Avoiding overreliance on celebrity benefits and boring design. 


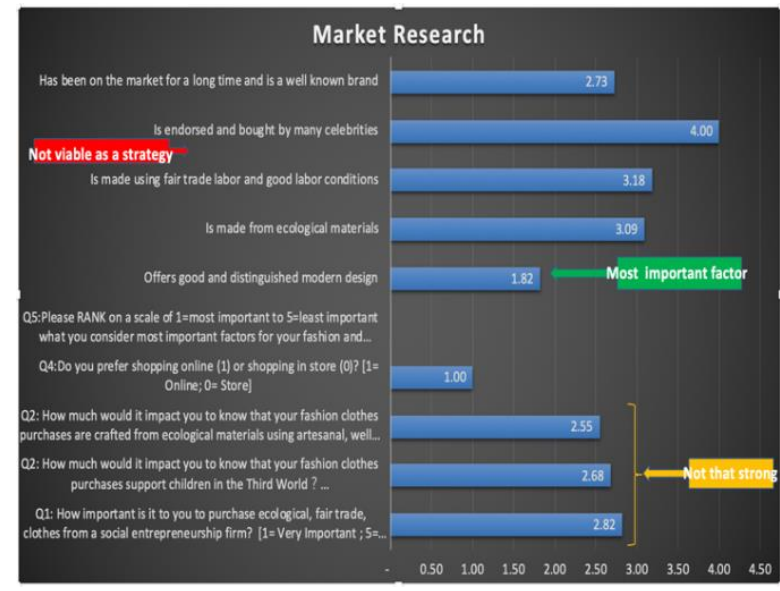

Figure 6 Brand "Regenerate"Summary of Market Research Create by Author

\section{BUSINESS PLAN}

The most logical business plan at the moment is to continue and consolidate the partnership with Burberry and launch a high-end luxury brand. If brands have an opportunity, they can consider branching brands, One focusing on luxury clothing (with Burberry over the world) and the other on affordable clothing (with Barbour / The local). Regarding financial management, the company's income comes from three sources: Clothes sale (Burberry), Clothes sale (Local) and Celebrity/social. Social donation (50\%) Brand improving (Advertising/Marketing etc.)(15\%) Establish/maintain partnerships with other brands. (15\%) and New product development (20\%) [9].

Goal is the most important factor for continuous improvement, and Regenerate's current smart goal are

1. Cooperated with Burberry, owned more than 10 local offline stores in the UK and established the official website for sales.

2. Entering the Enveloping Offline Stores and Conveyor Compressor with Shipping Company.

3. Mainly China and Japan, and set up stores. 4. Achieves annual revenue of more than $\$ 100$ million [10].

\section{CONCLUSION}

This paper analyzes the advantages and disadvantages of brands' Regenerate ', identifies the most suitable partners for them based on existing business models and strategies, and proposes the most efficient business methods. Research develops more focused and detailed goals for 'Regenerate' with comprehensive market research so that it can be sold worldwide. The highlight of paper is how to analyze existing information to help an entrepreneur or a brand find brand value and cater to the market to become a hot and unique brand [7]. This paper gives some inspiration to those who are starting their own businesses or are willing to, help them complete the promotion of their companies or brands. If further research is conducted, it will focus more on brand innovation and brand cooperation.

\section{REFERENCES}

[1] Simply Business Editorial Team 2021 How to start a clothing brand: the 9-step plan https://www.simplybusiness.co.uk/knowledge/articl es/2021/06/how-to-start-clothing-business/

[2] Noah Parsons 2021 What Is a SWOT Analysis and How to Do It Right https://www.liveplan.com/blog/what-is-a-swotanalysis-and-how-to-do-it-right-with-examples/

[3] Adam, Nawal Abdalla. Innovation practices for survival of small and medium rises (SMEs) in the COVID-19 times: the role of external support. 27May 2021.

[4] Mishra, Shrutika, and A. R. Tripathi. AI business model: an integrative business approach. 8 June 2021.

[5] Peña, Antonio Rodríguez. Assessing the impact of corporate entrepreneurship in the financial performance of subsidiaries of Colombian business groups: under environmental dynamism moderation. 30 June 2021.

[6] Luxe Digital 2021 The 15 Most Popular Luxury Brands Online In 2021 https://luxe.digital/business/digital-luxuryranking/most-popular-luxury-brands/

[7] James Ashton 2020 What it means to be a Human leader https://www.strategybusiness.com/article/What-it-means-to-be-aHuman-leader

[8] Daniela Coppola 2021 E-commerce worldwide Statistics \& Facts https://www.statista.com/topics/871/onlineshopping/

[9] Szirmai, Adam, et al. Entrepreneurship, Innovation, and Economic Development: Overview. Apr. 2011. Academic Search Complete.

[10] Gabriel Farias Iribarren 2016 Organization and structure of a fashion brand or company https:/gabrielfariasiribarren.com/en/organizationand-structure-of-a-fashion-brand-or-company/ 